\title{
A Fundamentação dos Direitos Humanos Segundo Alexy
}

\author{
Davi Marcucci Pracucho \\ Mestre em Direito, com área de concentração em Direitos Humanos, pela Fundação Universidade Federal \\ de Mato Grosso do Sul (UFMS). Bacharel em Direito pela Universidade de São Paulo (USP) - Faculdade de Direito \\ do Largo São Francisco. Procurador da República - membro do Ministério Público Federal. Ex-Defensor Público no Estado \\ de São Paulo.pracucho@gmail.com
}

Robert' Alexy é conhecido, no Brasil, principalmente em razão da sua teoria dos princípios, desenvolvida na interpretação dos direitos fundamentais. Na sua vasta obra, para além desse campo, todavia, o jusfilósofo alemão debruçou-se, outrossim, sobre os direitos humanos, especificamente sobre a sua fundamentação, objeto do presente artigo. Partindo da premissa de que, embora a efetivação dos direitos humanos seja crucial, dela não se dissocia o problema da fundamentação - vale dizer: existe uma complementaridade entre a fundamentação e a efetivação dos direitos humanos -, procede-se, neste trabalho, a uma leitura da fundamentação dos direitos humanos em Alexy, antes a situando na sua Teoria do Direito e na filosofia do direito em geral, e objetivando, ao fim, evidenciar, também no pensamento do professor tedesco, aquela relação de complementariedade entre fundamentação e efetivação, questões que se pressupõem e influenciam reciprocamente e que ambas encontram respostas coerentes e racionais na Teoria Discursiva do Direito.

Palavras-chave: Direitos humanos. Fundamentação. Alexy.

\section{THE FOUNDATION OF HUMAN RIGHTS ACCORDING TO ALEXY}

\section{ABSTRACT}

Robert Alexy is known in Brazil mainly due to his theory of the principles developed in the interpretation of fundamental rights. However, in his extensive work, beyond that field, the german philosopher of law also studied the human rights. Specifically, its foundation, the object of this article. Thus, starting from the premise that although the realization of human rights is crucial, it does not dissociate the problem of its foundation - that is to say: there is a complementarity between the foundation and the realization of human rights - this work reads the foundation of human rights in Alexy; however, before, places it in his theory of law and philosophy of law in general, aiming, at the end, to show, also in the thought of the german professor, that complementary relationship between foundation and realization, questions that presuppose and influence each other and that both find coherent, rational, answers in the discursive theory of law.

Keywords: Human rights. Foundation. Alexy.

\section{SUMÁRIO}

1 Notas introdutórias. 20 pós-positivismo jurídico e a Teoria do Direito de Alexy. 3 A Teoria Discursiva do Direito de Alexy. 4 A fundamentação dos direitos humanos segundo Alexy. 5 Considerações finais. 6 Referências. 


\section{NOTAS INTRODUTÓRIAS}

É célebre a declaração de Bobbio (2004), em A era dos direitos, de que o problema grave do nosso tempo, com relação aos direitos humanos, não é mais o de fundamentá-los, e sim o de protegê-los. Não que o problema da fundamentação tenha deixado de existir, ressalva o filósofo de Turim - pelo contrário: segundo o mestre italiano, ele é ineludível - mas se pode afirmar que, desde a Declaração Universal dos Direitos Humanos, aprovada em 10 de dezembro de 1948 pela Assembleia Geral das Nações Unidas e sucedida por diversas outras declarações solenes de aspiração universal, tal problema, ao menos em um certo sentido, restou resolvido, sendo mais preocupante, desde então, para além de saber o quê, quais e quantos são os direitos humanos, descobrir e estabelecer instrumentos eficazes para impedir a sua contínua violação.

Ocorre que, por mais preocupante que seja, hoje, o problema da efetivação dos direitos humanos, ele não prescinde da questão da fundamentação. Como assinala Torrado (2012), não existe uma verdadeira proteção dos direitos humanos sem que previamente se afirme a exigência de atribuir ao ser humano as garantias que, por sua natureza, lhe correspondem.

Nesse sentido, observa-se, com Cançado Trindade (2015), que o início do século 21, ao mesmo tempo em que vem marcado por novos conflitos e crises humanitárias e pela generalização da violência, traz um jus gentium no qual a pessoa emerge como o sujeito de direitos central, dotado de direitos oriundos diretamente do direito internacional e de capacidade para vindicá-los. Trata-se de um direito internacional cada vez mais humanista e universal, preocupado em identificar e realizar valores e metas comuns superiores relativamente a cada ser humano em particular e à humanidade como um todo.

Retomando as lições de Torrado (2012), consigna o professor espanhol que, sendo os direitos humanos uma realidade complexa - ética, política e jurídica - a sua fundamentação pode ter diferentes enfoques, mencionando, no seu trabalho, as perspectivas filosófica-jurídica, científica-jurídica, filosófica-política e ética-religiosa. Nesses prismas, sem prejuízo de outros, pode-se acrescentar o antropológico, no qual, as mais das vezes, é considerada a diversidade de comunidades morais existente entre as nações e mesmo no interior de uma nação, como se vê em Segato (2006). Problematizando ainda mais a questão, Santos (2014) descortina o caráter hegemônico do discurso de direitos humanos de matriz ocidental e liberal, mostrando as ilusões criadas diante do seu verdadeiro caráter monocultural e monológico.

Este, porém, não é um trabalho sociológico ou antropológico. Trata-se de um ensaio jurídico; mais precisamente, jusfilosófico.

A proposta, aqui, é proceder a uma leitura da fundamentação dos direitos humanos no pensamento de Robert Alexy, "reconhecido como um dos mais destacados jusfilósofos da atualidade na Alemanha e considerado um dos grandes conhecedores da Filosofia do século 20, isto é, da Filosofia da Linguagem" (TOLEDO, 2013, p. 2). Suas categorias e terminologia, anota Barroso (2014), encontram-se incorporadas na linguagem de diversas cortes constitucionais mundo afora (incluso o Supremo Tribunal Federal), sendo na interpretação constitucional, especificamente na interpretação dos direitos fundamentais, onde se operou a sua contribuição mais revolucionária, via teoria dos princípios. 
A obra de Alexy é vasta, quantitativa e qualitativamente. Em monografias e em um sem-número de artigos, para além da interpretação e aplicação dos direitos fundamentais, o jusfilósofo germânico trata, inter alia, do conceito e da natureza do direito, da teoria do discurso prático geral, da argumentação jurídica e da teoria dos direitos humanos e fundamentais (ALEXY, 2015c), esta última objeto da presente exposição.

Antes, entretanto, de adentrar na teoria dos direitos humanos de Alexy propriamente dita, percorre-se um breve itinerário, em uma aproximação dedutiva, que passa por situar a teoria objeto de estudo, primeiro, no cenário da filosofia do direito em geral e, em seguida, no âmbito da Teoria do Direito do próprio autor.

O que se espera, ao final, independente das críticas que se possam dirigir à concepção apresentada - mormente as advindas de olhares vinculados a outras correntes ideológicas ou de análises filiadas a outros paradigmas científicos - é evidenciar, também na Teoria do Direito de Alexy, a complementaridade entre a fundamentação e a efetivação dos direitos humanos.

\section{PÓS-POSITIVISMO JURÍDICO E A TEORIA DO DIREITO DE ALEXY}

No século 19 e na primeira metade do século 20, o positivismo jurídico foi a teoria que dominou a filosofia do direito ocidental. Para responder à pergunta o que é o direito?, afirmavam as orientações positivistas, em geral, dois elementos definidores fundamentais: (i) o direito é uma criação humana - no dizer positivista: posto pelo ser humano; e (ii) o direito pode ser adequadamente compreendido pelo método das chamadas ciências naturais ou fisicas, desenvolvido nos séculos 18 e 19, conhecido como positivismo, que, para alcançar a objetividade do conhecimento, busca eliminar todas as considerações de ordem subjetiva, especialmente os valores, que possam surgir no pensamento do cientista (MORRISON, 2006).

Na obra O positivismo jurídico: lições de filosofia do direito, Bobbio (1995) explica que, enquanto método, o positivismo jurídico é a postura científica ante o direito, considerando o mesmo como um conjunto de fatos, fenômenos ou dados sociais em tudo análogos àqueles da natureza, devendo o cientista do direito, tal qual o cientista da natureza, abster-se completamente de formular juízos de valor, de modo que, assim tomado, o direito não é entendido como um valor; pelo contrário: é uma realidade absolutamente avalorativa.

Acrescenta que, não sendo adotado o método positivista para o estudo do direito, faz-se filosofia ou ideologia, mas não ciência do direito.

A principal consequência desse método - prossegue o filósofo de Turim - é a formulação de uma teoria da validade das normas jurídicas de caráter estritamente formal, isto é, fundada em critérios extraídos unicamente da estrutura formal do direito, prescindindo do seu conteúdo. É a dita teoria do formalismo jurídico.

Ainda segundo o mestre italiano, Kelsen, com a sua teoria pura do direito (também conhecida como normativismo jurídico), representou o apogeu do positivismo jurídico, depois do que o movimento entrou em crise, iniciando a sua decadência. As investigações levadas a efeito pelo austríaco tiveram os méritos, afirma-se, de separar o problema da validade do direito do da justiça (BOBBIO, 2008) e de proceder a uma análise estrutural deveras elucidativa da estática e dinâmica jurídicas. Apesar de assinalar a preocupação marginal da teoria pura 
com a análise funcional do direito - que resultou no conceito de ordenamento coativo -, registra Bobbio (2007) que ela não exclui que se possa operar semelhante exame, além de ser compatível com os resultados porventura obtidos, a exemplo da função promocional, mais nítida no Estado contemporâneo.

O fato, entretanto, é que, a despeito dessas virtudes, o positivismo jurídico, no qual se inclui o normativismo kelseniano, embora pareça fornecer uma metodologia relativamente simples para identificar o direito, teve os seus alicerces abalados pela observação de Heidegger de que todo fenômeno social pode ser objeto de interpretações diferentes e multifacetadas. Nesse contexto, de acordo com os seus críticos, o positivismo jurídico enfraqueceu a capacidade de pensar o fenômeno jurídico, sendo necessárias novas formas de interpretação para compreender o papel do direito (MORRISON, 2006).

Os resultados limitados do positivismo jurídico passam a ser questionados. A teoria pura do direto, o ápice do movimento, passa a ser vista como doutrina inútil: Que sentido útil tem uma teoria jurídica não orientada para a dogmática, isolada desta, que não explora nem problematiza a realidade?, indaga Losano (2009, p. 20); ainda é vista, igualmente, como doutrina do status quo jurídico. Nas palavras de Losano (2011, p. XXIX): “Quem descreve e enumera simplesmente está delegando a outrem o ato de prescrever e escolher; [...] diante da inércia do outro, prescreve e escolhe quem tem o poder".

Abre-se a filosofia do direito, então, por um lado, ao mundo dos valores ético-políticos (com as críticas de Dowrkin a Hart) e, por outro, ao mundo dos fatos (com Weinberger e MacCormick). É o pós-positivismo jurídico (FARALLI, 2006).

Nesse cenário, Alexy (2011) advoga que a chamada dogmática analítica (sistemática-conceitual), objeto central do método positivista, não basta ao caráter prático da ciência do direito, que, para cumprir a sua tarefa prática de forma racional, precisa também da dogmática empírica (cognição do direito positivo válido) e da dogmática normativa (práxis jurídica, determinação da decisão correta em um caso concreto).

A preocupação com a tarefa prática da ciência do direito, bem como com a racionalidade, pode explicar a matriz filosófica do autor, a saber, Habermas, com ele compartilhando a indissociabilidade entre procedimento de justificação e confronto racional entre posições de valor (PALOMBELLA, 2005). O conceito habermasiano de ação (e de racionalidade) comunicativa, por seu turno, pode ser considerado um exercício da filosofia crítica, ou razão crítica, posto que "a dimensão cardeal da 'comunicação' amplia, de maneira prototípica, a relação de intersubjetividade que Kant entrevira sem explorar totalmente" (GOYARD-FABRE, 2006, p. 304).Em última análise, o ponto de partida é acreditar na ideia de uma razão crítica, afastando-se o relativismo (MARYIOLI, 2005).

Orientado por essas balizas teóricas e procurando fazer frente ao caráter prático da ciência do direito, Alexy fornece relevante contribuição à racionalidade do discurso jurídico, especificamente, segundo Palombella (2005), mediante uma filosofia (hermenêutica) analítica do direito, entendendo o raciocínio jurídico como um caso especial do raciocínio prático e assim tratando da estrutura lógica dos argumentos e das regras de argumentação. 
O professor da Universidade de Pisa relata que, no ensaio The Foundation of Legal Reasoning, escrito em 1981 por Alexy, em coautoria com Aarnio e Peczenik, conquanto admitam os autores que não existam regras de justificação aptas a conduzir a uma só conclusão, é necessário que as transformações sejam justificadas racionalmente, isto é, por meio de regras de justificação racional que produzam um discurso racional idôneo a conferir aceitabilidade ao raciocínio jurídico. Nesse processo, entrelaçam-se tanto regras inerentes à racionalidade lógica quanto regras voltadas à racionalidade dita discursiva, da qual tratou, sobretudo, Alexy, nela incluindo, entre outros, o requisito da congruência (coherence). Trata-se, sem prejuízo do respeito às demais regras da racionalidade - lógica e discursiva -, da compatibilidade com o material interpretativo, quer dizer, as fontes credenciadas do direito.

A teoria de Alexy é considerada procedimental (procedural), completa Palombella (2005), o que significa que indica um procedimento determinado, um sistema de regras necessário para se fazer uma justificação racional. Assim, na verificação da racionalidade uma justificação ocorre pela análise da observância das regras que disciplinam o procedimento argumentativo racional. É, portanto, uma hermenêutica analítica, diferindo da denominada hermenêutica dialética, a exemplo da de Gadamer e Esser, em que a verificação não envolve a forma dos argumentos, e sim o seu conteúdo.

Diferencia-se a Teoria do Direito de Alexy, outrossim, da concepção sociológica de Luhmann. De acordo com Faralli (2006), enquanto a última concebe o direito como um subsistema social autônomo, que opera segundo o código próprio e específico do direito/não direito, a primeira vê no fenômeno jurídico uma estrutura aberta ao mundo externo das razões não jurídicas (morais, ético-políticas, pragmáticas, etc.). Essa abertura vem, especialmente, dos princípios, entendidos como preceitos de otimização que exprimem decisões valorativas.

A propósito, narra a professora italiana que a ênfase de Alexy no conteúdo valorativo determinante dos princípios rendeu-lhe a crítica de Habermas, para quem a teoria do jusfilósofo de Oldemburgo promove a subordinação do direito à moral, que, ainda não completamente liberada do jusnaturalismo, é tendenciosa.

Faralli (2006, p. 11) insere a obra de Alexy no que denomina "constitucionalismo como teoria específica do direito e sua distinção do positivismo (ou legalismo)", apontando como precursor dessa abordagem Dworkin, com a sua concepção do direito como integridade. A autora contextualiza os estudos do alemão no final dos anos 80, à luz do debate sobre o papel do Tribunal Constitucional Federal (Bundesverfassungsgericht) e a interpretação da sua jurisprudência. Assinala que o principal traço desses estudos, também presente nas demais abordagens constitucionalistas, é o reconhecimento do aumento da complexidade da estrutura normativa dos sistemas jurídicos contemporâneos, ligada à introdução de princípios nas Constituições e à diferenciação destes das regras.

Esse traço principal é desdobrado em outros três pela professora de Bolonha, consistindo eles na defesa: da conexão entre direito e moral, da importância dos processos de aplicação do direito e da vinculação do legislador aos princípios e direitos constitucionais.

A conexão entre direito e moral decorre da dimensão da correção moral do direito, assim como da abertura a conteúdos morais levada a efeito pelos princípios e direitos invioláveis dos indivíduos. 
A importância dos processos de aplicação do direito resulta justamente da conexão entre direito e moral, dessa abertura, sendo necessárias novas formas de decisão, a exemplo da ponderação de princípios (balancing).

A vinculação do legislador aos princípios e direitos constitucionais, por fim, é produto da estrutura político-constitucional, sendo realçado pelas teorias constitucionalistas, ademais, o papel decisivo do Poder Judiciário para a efetivação daqueles princípios e direitos, ainda que, para tanto, tenha de decidir em contraste com as decisões legislativas e com a lei.

Uma vez contextualizado o pensamento de Alexy no âmbito da filosofia do direito, passa-se a uma leitura da sua obra nos seus principais aspectos, nela buscando identificar o lugar da fundamentação dos direitos humanos, objeto central deste artigo.

\section{A TEORIA DISCURSIVA DO DIREITO DE ALEXY}

Explica Trivisonno (2015a) que, apesar de vasta, incluindo uma diversidade de artigos, a obra de Alexy pode ser descrita por meio de três monografias: Teoria da argumentação jurídica: a teoria do discurso racional como teoria da fundamentação jurídica (1978), Teoria dos direitos fundamentais (1985) e Conceito e validade do direito (1992).

Na primeira delas (ALEXY, 2013), o jusfilósofo tedesco propõe-se a investigar se a argumentação jurídica racional é possível e com que alcance. Para tanto, enfrenta essa questão, primeiramente, em termos de argumentação prática geral, após o que, a partir desta, formula uma teoria da argumentação jurídica.

O impulso para tal investigação é a constatação de que a aplicação das normas, a hermenêutica jurídica, envolve valorações e juízos de valor, indagando-se, então, se essas valorações são passíveis de fundamentação racional.

No campo da argumentação prática geral, o autor visita teorias da ética analítica, incluindo Stevenson, Hare, Toulmin e Baier, bem como a teoria consensual da verdade de Habermas e a teoria da argumentação de Perelman. A partir delas, procede a uma síntese em uma teoria do discurso prático racional geral, ressalvando, não obstante, os seus limites. Esclarece que o seguimento das regras da teoria por ele esboçada aumenta a probabilidade de alcançar um acordo racional nas questões práticas, mas não garante que se possa obter um acordo para todas as questões tampouco que os acordos alcançados sejam definitivos e irrevogáveis. Isso porque algumas regras somente podem ser seguidas parcialmente, porque não estão determinados todos os passos da argumentação e porque todo discurso parte de concepções normativas mutáveis, historicamente dadas.

Para formular a sua teoria da argumentação jurídica, Alexy sustenta a chamada tese do caso especial, segundo a qual o discurso jurídico é um caso especial do discurso prático geral. Quer dizer: o discurso jurídico não deixa de ser um discurso prático, envolvendo questões práticas, sobre o que deve ou não deve ser feito. Envolve, ademais, a denominada pretensão de correção, ou seja, pretende-se, no discurso prático e jurídico, afirmar ou propor um enunciado correto, racional. Por outro lado, como caso especial, apresenta um elemento diferenciador, a saber: a pretensão de correção, no discurso jurídico, expressa-se na racionalidade no contexto de um ordenamento jurídico vigente, o que atrela a argumentação racional à legislação, aos precedentes judiciais e à dogmática jurídica. 
Com isso, embora não possam ser eliminadas, as deficiências do discurso prático geral amenizam-se consideravelmente no discurso jurídico. A teoria do discurso jurídico racional, explica o autor, é uma teoria da fundamentação jurídica, não um procedimento que garante a segurança do resultado. Até porque, argumenta, nem mesmo nas ciências naturais, frequentemente consideradas as verdadeiras ciências, forma-se uma segurança definitiva. Assim, "não é a produção de segurança o que constitui o caráter racional da Ciência do Direito, mas o cumprimento de uma série de condições, critérios ou regras" (ALEXY, 2013, p. 284-285). 0 autor complementa afirmando que as inseguranças da teoria do discurso prático geral, que também afetam o discurso jurídico, não tornam inútil a teoria do discurso como critério de correção: serve a teoria do discurso, especialmente, como critério negativo, identificando os argumentos irracionais, além do que as suas deficiências nada mais fazem do que mostrar que o juízo sobre a correção de uma decisão tem sempre um caráter provisório e, desse modo, refutável.

Vê-se que Alexy, ao contrário de Dworkin, entende não ser possível uma única solução para cada caso, propondo uma ideia regulativa (TRIVISONNO, 2015b).

$\mathrm{Na}$ obra Teoria dos direitos fundamentais (2011), o pensador alemão prossegue voltado ao caráter prático da ciência do direito, desta feita procurando colaborar com a obtenção de respostas racionalmente fundamentadas às questões relativas aos direitos fundamentais previstos no texto da Constituição da República Federal da Alemanha. Justifica-se, então, a investigação - assinala o autor - porque, de um lado, tais direitos, de acordo com o texto constitucional, são diretamente aplicáveis, vinculam os poderes Legislativo, Executivo e Judiciário e essa vinculação encontra-se sujeita ao controle do Tribunal Constitucional Federal, e porque, de outro, consubstanciam-se os direitos fundamentais em disposições abertas, desprovidas de um conteúdo inequívoco, à medida que a jurisprudência do Tribunal Constitucional, apesar da sua contribuição para diminuir o problema da abertura, é ela própria, também, aberta, servindo de base para diferentes tomadas de posição sobre uma mesma questão.

A colaboração de Alexy, nessa empreitada, é a famosa teoria dos princípios, no centro da qual estão a distinção entre regras e princípios e a máxima mais importante da interpretação dos direitos fundamentais, a da proporcionalidade.

Regras são normas jurídicas que contêm determinações, exigindo que algo seja feito de uma forma precisa; nem mais, nem menos, de modo que ou são atendidas ou não atendidas, sem meio-termo. Por consequência, quando duas regras conflitam entre si, por exemplo uma permitindo e a outra proibindo algo, a solução passa ou pela existência ou introdução de uma cláusula de exceção que elimine o conflito ou pela declaração da invalidade de uma das regras, eliminando-a do ordenamento jurídico.

Princípios, de outro lado, são normas jurídicas que veiculam mandamentos (em sentido amplo: permissões ou proibições) de otimização, ordenando que algo seja realizado na maior medida possível, porque consideram as possibilidades fáticas e jurídicas existentes. As possibilidades jurídicas são outros princípios, bem como regras, que com eles possam colidir. De sorte, podem ser atendidos em diferentes graus, de acordo com as possibilidades: totalmente, muito, pouco, etc. Por conseguinte, havendo dois princípios que colidam reciprocamente, a busca pelo atendimento de ambos, conforme as possibilidades, faz com que um deles tenha de ceder, sem, porém, que se tenha introduzida uma cláusula de exceção ou que seja declara- 
do inválido. Qual dos princípios tem de ceder depende do peso que cada um deles apresenta no caso concreto, posto que os mesmos princípios colidentes podem ter distintos pesos em diferentes casos concretos, ora prevalecendo um, ora outro.

Nota-se que, para as regras, fala a Teoria dos direitos fundamentais em conflitos, contradições que ocorrem no plano da validade, pois não é logicamente possível que um ordenamento jurídico contenha, ao mesmo tempo, duas regras contraditórias entre si igualmente válidas. Já no que concerne aos princípios, as contradições dão-se entre princípios igualmente válidos, não havendo propriamente um conflito (exclusão recíproca no plano lógico da validade), e sim uma colisão, podendo ser vista como um encontro de vetores opostos, uma disputa de espaço. Essa disputa tem lugar no caso concreto. De acordo com as circunstâncias fáticas ou jurídicas, cada um dos princípios colidentes assume um peso. A dimensão peso, em que se opera a colisão de princípios, é tomada emprestada de Dworkin, da obra Taking Rights Seriously.

Da diferença estrutural entre regras e princípios, extrai o autor o seu distinto caráter prima facie: enquanto as primeiras trazem mandamentos definitivos, os segundos nunca são, em si mesmos, razões definitivas para uma decisão. Como sempre apresentam razões que podem ser afastadas por razões antagônicas, os direitos decorrentes de princípios são sempre direitos prima facie.

Do mesmo modo, a conhecida máxima da proporcionalidade - com as suas três máximas parciais: adequação, necessidade e proporcionalidade em sentido estrito - decorre da própria natureza dos princípios. A adequação e a necessidade (mandamento do meio menos gravoso) decorrem da exigência de otimização ante as possibilidades fáticas. A proporcionalidade em sentido estrito (sopesamento, ut supra) decorre da exigência de otimização perante as possibilidades jurídicas - outros princípios e regras.

Ainda na mesma obra, Alexy (2011, p. 153) acrescenta que princípios e valores se encontram intimamente relacionados, sustentando que a única diferença entre o modelo de princípios e o modelo de valores é o caráter deontológico (dever ser) de um e o caráter axiológico (critério de valoração) do outro: "aquilo que, no modelo de valores, é prima facie o melhor é, no modelo de princípios, prima facie devido; e aquilo que é, no modelo de valores, definitivamente o melhor é, no modelo de princípios, definitivamente devido". Assim sendo, quando se fala em uma colisão ou em um sopesamento de princípios, pode-se falar em uma colisão ou em sopesamento de valores, troca essa que, de resto, é comum nos enunciados formulados no cotidiano da prática jurídica.

A relação entre princípios e valores, assim como a possibilidade de fundamentação racional das valorações e do discurso jurídico (desenvolvida na Teoria da argumentação jurídica), é retomada na obra Conceito e validade do direito, na qual Alexy (2009), ao contrário dos positivistas, defende existir uma conexão necessária entre direito e moral.

No intento de demonstrar a sua tese, o autor vale-se de três argumentos principais: o da correção, o da injustiça e o dos princípios.

$\mathrm{O}$ argumento da correção, aplicado na perspectiva do observador de um sistema (quer dizer: na visão de alguém de fora, que não participa desse sistema), mostra que, para ser direito, não basta a um sistema de normas a qualidade da coerção (força, eficácia), devendo formular, necessariamente, uma pretensão de correção. Pretensão de correção significa que 
os atos praticados com base no direito (atos jurídicos) trazem implícitos em si a asserção de que são procedimental e substancialmente corretos. Sem pretensão de correção, ainda que formulada com base em normas possivelmente injustas, tem-se um sistema no qual não existem ou perdem sentido as distinções correto/incorreto, justo/injusto, desparecendo, até mesmo, o dever ser, dado que tudo se reduziria a poder, vontade e decisão (ALEXY, 2014). Desse modo, encontram-se conceitualmente excluídas do direito - ou seja: absolutamente não constituem direito - situações nas quais não se pode observar uma pretensão de correção, a exemplo do chamado ordenamento absurdo (simples relação de dominação, sem finalidade, direitos e deveres) e do ordenamento predatório (relação de dominação com uma finalidade; ainda sim, sem qualquer direito para os dominados).

Trata-se de situações-limite, é verdade, mas, além de já constituírem uma limitação da tese positivista na perspectiva do observador, o argumento da correção desempenha um papel central na perspectiva do participante de um sistema jurídico. São relevantes as suas consequências sistemáticas, vale dizer, em associação com os outros dois argumentos (o da injustiça e o dos princípios); representando, ademais, um nexo entre as duas perspectivas.

Assim é que o argumento da correção - como visto, argumento conceitual - complementa o argumento da injustiça, este empregado na perspectiva do participante e de forma normativa, o que significa ser um argumento que, embora não demonstre uma conexão conceitualmente necessária entre direito e moral, demonstra que essa conexão é necessária para que se alcance determinado objetivo. Há aí, então, uma vinculação normativamente necessária entre direito e moral.

Apoia-se o argumento da injustiça, inicialmente, na conhecida fórmula de Radbruch, consoante à qual, em síntese, uma norma perde o seu caráter jurídico quando transgride um limiar insustentável de injustiça. Dito de outro modo: a injustiça extrema não é direito. Ao lado de outros argumentos normativos, agrega-se a isso que a verificação do limiar de injustiça extrema é pautada por exigências morais mínimas passíveis de fundamentação racional, como ocorre com o componente nuclear dos direitos humanos elementares. Inerente a esse processo, está a pretensão de correção: toda sentença, como ato jurídico que é, formula, necessariamente, uma pretensão de correção, sendo certo que uma sentença que veicule uma injustiça insustentável ou extrema não atende, nessa medida, à pretensão de correção.

Isso porque toda pretensão de correção encerra, em todos os contextos, um mesmo conteúdo: uma pretensão de fundamentabilidade, ou seja, de fundamentação, de resolver questões práticas de modo correto (ALEXY, 2015a), e porque todo sistema jurídico minimamente desenvolvido inclui, necessariamente, normas com a estrutura de princípios (vide supra) e, por consectário, assim permite considerações morais. Esses aspectos podem ser mais bem visualizados no argumento dos princípios.

De acordo com o argumento dos princípios, que o autor também situa na perspectiva do participante, e de forma conceitual, todo sistema jurídico minimamente desenvolvido, como dito, contém princípios, dentre os quais se encontram aqueles que integram uma moral. Dados o caráter prima facie desses princípios e a necessidade de sopesamento entre eles, tem-se que a pretensão de correção jurídica associa-se, no caso, à pretensão de correção moral; vale dizer: pretensão de aplicação de uma moral correta; não, porém, qualquer moral. 
Como visto, a pretensão de correção implica pretensão de fundamentabilidade, de fundamentação racional; in casu, de uma moral fundamentável racionalmente. Na perspectiva do participante, observa-se a conexão entre o direito e não uma determinada moral conteudística, e sim entre o direito e a ideia de uma moral correta, no sentido de uma moral fundamentada, na qual fracassa um considerável número de argumentos irracionais e injustos. Essa ideia de moral correta, ademais, assume um caráter regulador, como um objetivo a ser alcançado na pretensão de correção.

Somando-se a esse quadro o argumento da injustiça, observa-se que, antes do limiar de injustiça extrema, o não atendimento da pretensão de correção, embora leve a uma imperfeição jurídica, não acarreta a perda da qualidade jurídica - ou, ainda, da validade. A norma produzida continua a ser direito. A essa conexão entre direito e moral o autor denomina qualificadora - o fenômeno não deixa de ser classificado como direito, mas é qualificado como um direito imperfeito. Por outro lado, ao romper o limiar de injustiça extrema, a norma produzida, para além de não satisfazer a pretensão de correção, deixa de ser direito, perdendo a sua validade jurídica. A conexão entre direito e moral nesses termos é dita pelo autor classificadora - o conteúdo moral afeta a própria identificação, classificação, do fenômeno, situando-o no direito ou no não direito.

Nas três obras, aqui brevemente interpretadas, é possível notar a centralidade da teoria do discurso. Primeiro, enquanto possibilidade de argumentação moral e jurídica racional, ao mesmo tempo em que afasta das questões práticas argumentos injustos e irracionais. Segundo, como mecanismo inseparável da interpretação e aplicação dos direitos fundamentais, via máxima da proporcionalidade, incluindo o sopesamento entre princípios. Terceiro, aparecendo como elemento-chave na satisfação da pretensão de correção, esta inerente ao direito e cujo conteúdo essencial é a fundamentabilidade.

Mencionou-se, linhas atrás, que, para Alexy, pauta-se por exigências morais mínimas, passíveis de fundamentação racional, a verificação do limiar de injustiça extrema, citando como exemplo o componente nuclear dos direitos humanos elementares.

Daí podem ser extraídas duas observações: segundo o autor, transgride-se o limiar de injustiça extrema quando se viola o núcleo dos direitos humanos elementares; e o componente nuclear dos direitos humanos elementares é passível de fundamentação racional.

Uma tal fundamentação também foi objeto de estudos pelo jusfilósofo alemão, e, igualmente, por meio da teoria do discurso.

\section{A FUNDAMENTAÇÃO DOS DIREITOS HUMANOS SEGUNDO ALEXY}

No ensaio Teoria do discurso e direitos do homem, Alexy (2015b) propõe-se a formular uma fundamentação teórico-discursiva (ou seja: com base na teoria do discurso) dos direitos humanos, o que passa por duas etapas: primeiro, a fundamentação das próprias regras do discurso prático, o ponto de partida da análise; e, segundo, a passagem das regras do discurso, das quais não resulta diretamente regra alguma para atuação (ou direito, portanto), para os direitos humanos. 
A fundamentação das regras do discurso prático repousa em três argumentos: um argumento transcendental, um argumento voltado à maximização da utilidade individual e uma tese antropológica.

Para a passagem das regras do discurso aos direitos humanos, vale-se o autor, igualmente, de três argumentos: da autonomia, do consenso e da democracia.

Antes de adentrar na fundamentação das regras do discurso prático, cumpre apresentar quais são essas regras, até porque elas servem de base, na segunda etapa, para a fundamentação dos direitos humanos.

Destaca Alexy (2015b, p. 103) que "a teoria do discurso é uma teoria procedimental da correção prática". Da correção prática significa a busca pelo correto para questões práticas, decisões (morais ou jurídicas, e.g.), sendo o correto entendido como o fundamentável racionalmente. Procedimental porque a teoria reúne um conjunto de condições que, se cumpridas, levam a um argumentar prático racional. Trata-se, desse modo, de uma teoria da argumentação racional e o seu objetivo é a imparcialidade do discurso.

Para assegurar tal objetivo, é necessário que exista liberdade e igualdade entre os participantes da argumentação, de modo que as mais importantes regras do discurso dizem, em síntese, que: todo aquele que pode se expressar tem permissão para participar dos discursos, introduzindo ou questionando afirmações, ou simplesmente manifestando colocações; e nenhum participante pode ser impedido de exercer essas prerrogativas por outro participante.

Nesse quadro de liberdade e igualdade entre os participantes do discurso, de um ponto de vista coletivo e sob condições ideais, tem-se que, para uma aprovação universal, a correção prática exige a seguinte regra: corretas são as normas que, em um discurso ideal, seriam consideradas corretas por participante. Essa regra corresponde, assinala o autor, ao princípio de Kant do poder doador de leis, segundo o qual somente pode ser doadora de leis a vontade popular universalmente unida, isto é, a vontade concordante e unida de todos, cada um decidindo sobre todos e todos sobre cada um.

Para fundamentar as regras do discurso prático, Alexy, como dito, recorre a três argumentos, os quais se complementam, porquanto o argumento transcendental, em que pese nuclear, é fraco, precisando ser reforçado pelos outros dois, o argumento da maximização da utilidade e o antropológico/empírico.

Segue, então, que deve ser explicado em que consiste o argumento transcendental e porque o autor o considera um argumento fraco.

O argumentar transcendental passa por sustentar a necessidade de um determinado ponto de partida, dele extraindo, depois, certas categorias ou regras.

No caso da teoria do discurso, o ponto de partida são os atos de falar e, especificamente, fazer afirmações. Tais afirmações somente são possíveis se algumas regras, nelas pressupostas, forem necessariamente cumpridas.

Essas regras decorrem da essência das afirmações, que é promover uma pretensão de verdade ou correção. Sem a pretensão de verdade ou correção, haveria, em uma afirmação, uma contradição performativa. Sucessivamente, dessa primeira regra podem ser deduzidas outras, a saber: a pretensão de fundamentabilidade (uma afirmação, pretendendo ser verdadeira ou correta, pressupõe algum fundamento, qualquer que seja, para tanto); o dever prima 
facie de fundamentar o afirmado, a pedido (pressuposto pela pretensão de fundamentabilidade); a igualdade de direitos na argumentação, a ausência de coerção e a universalidade da argumentação (fora dessas condições, a pretensão de correção não é atendida).

Ocorre que fazer afirmações e fundamentações é um ato possível, e faz parte da forma de vida mais geral das pessoas (em algum momento de sua vida, toda pessoa faz alguma afirmação ou pergunta por que?), porém, em tese, não se trata de uma realidade necessária, especialmente quando consideradas as situações concretas extremamente diferentes. Isso transforma o argumento transcendental em um argumento fraco e a teoria do discurso, a seu turno, em uma teoria do potencial da razão.

$\mathrm{O}$ argumento transcendental funcionaria bem se pudesse ser pressuposto que toda pessoa tem um interesse, preponderante sobre todos os outros interesses, de solucionar conflitos corretamente, no sentido justo. Isso, todavia, não pode ser validamente pressuposto, posto que o argumento transcendental, por si só, valida apenas hipoteticamente as regras do discurso prático, sendo faticamente limitado o seu alcance.

Por isso, entram em cena os outros dois argumentos. $\mathrm{O}$ argumento antropológico ou empírico começa afirmando que se, de um lado, não se pode pressupor o interesse de todos na correção (otimismo infundado), de outro não se pode, do mesmo modo, assumir que ninguém tenha tal interesse (pessimismo infundado). Interesse na correção existe, em alguma medida, entre governantes e governados. Posto isso, certamente é melhor para os primeiros fazer fundar o exercício da sua dominação, ao menos aparentemente, em argumentos, ainda que ruins, pois o mero exercício da força é custoso, instável e, enfim, arriscado. Uma legitimação institucional, e não subjetiva - os dominadores podem não acreditar, intimamente, nos argumentos, mas os afirmam para eliminar ou reduzir as desvantagens do simples uso da força. Tem-se, aqui, associado ao argumento do interesse na correção, o argumento da maximização da utilidade individual.

Ambos os argumentos, em conjunto, reforçam o argumento transcendental, dando validez objetiva às regras do discurso prático. Em resumo: deve se valer das regras do discurso, que fazem parte da forma de vida mais geral das pessoas, tanto aquele que tem interesse na correção como aquele que não tem, visto lhe ser vantajoso fazê-lo, a longo prazo, do ponto de vista da maximização da utilidade individual.

Tendo como ferramentas as regras do discurso prático, dotadas de validez objetiva, o professor tedesco parte, em seguida, para a fundamentação dos direitos humanos propriamente dita. Anota, nesse mister, a necessidade de fazer uso de outras premissas, dado que as regras do discurso têm caráter procedimental, delas não se podendo extrair diretamente alguma regra de atuação. Registra, ademais, que a fundamentação dos direitos humanos passa por dois problemas: o problema de conteúdo diz respeito a saber quais são esses direitos e o problema de forma nada mais é do que a necessidade de transformar tal conteúdo em direito positivo, para que os direitos possam se desenvolver e ter força plena.

O problema de forma é mais simples, resolvendo-se, em última análise, na necessidade do próprio direito positivo, que surge de três problemas: do conhecimento (como agir), da imposição (fazer cumprir) e da organização (necessidade de alcançar exigências morais e objetivos coletivos). A renúncia à solução desses problemas redundaria na anarquia. 
Quanto ao problema de conteúdo, o autor adianta que a sua preocupação, no ensaio, é com os direitos humanos discursivamente necessários (o que chama de fundamentação imediata - diretamente a partir da teoria do discurso), e não com os direitos meramente possíveis no discurso, vale dizer, aqueles que exsurgem do exercício teórico-discursivo no âmbito de um determinado processo político (fundamentação mediata), e elege, para tal desiderato, três premissas: da autonomia, do consenso e da democracia.

A premissa ou o princípio da autonomia é a ideia de que quem participa seriamente de um discurso pressupõe a autonomia do seu parceiro, o que significa aceitar que o outro determine o seu comportamento somente pela livre adoção de normas por ele consideradas válidas após suficiente deliberação e reflexão. Fundamenta-se tal princípio no fato de que a participação séria em um discurso implica não a simples busca de um convencimento pessoal, mas, sim, um consenso discursivamente criado e controlado, com possibilidade permanente de revisão discursiva, assim protegido de equívocos duradouros. Quer isso dizer, então, que o interesse na correção do discurso engloba o interesse na autonomia dos participantes. Tudo isso, de novo, de um ponto de vista institucional, objetivo, e não subjetivo, motivacional, entrando aqui, também, o argumento da maximização da utilidade individual quanto àquele que não participa genuinamente do discurso.

Ao princípio da autonomia corresponde um direito geral à autonomia, que também pode ser designado direito de liberdade geral, sendo o direito humano fundamental mais geral: "cada um tem o direito de apreciar livremente o que é ordenado e o que é bom e de atuar correspondentemente", formula Alexy (2015b, p. 120). Trata-se de um princípio, um direito prima facie ( $v$. supra), que deve ser realizado na maior medida possível, mas podendo ser limitado em virtude da autonomia dos outros e de bens coletivos, sobre os quais exerce, entretanto, uma primazia prima facie. Além disso, do direito à autonomia decorrem outros direitos, de duas formas. A primeira são simples desdobramentos ou espécies de autonomia. A segunda, direitos necessários para que alguém possa atuar autonomamente, a exemplo do direito ao mínimo existencial e dos direitos fundamentais sociais. Em ambos esses processos, situam-se, também, os direitos da autonomia pública, como a liberdade de opinião, imprensa e reunião, o direito universal e igualitário ao voto, etc., abrindo-se a porta, nesse passo (processo político), da fundamentação mediata dos direitos humanos.

O argumento ou a premissa do consenso é a verificação, em um discurso ideal, de resultados necessários ou impossíveis. É empregado pelo autor para introduzir a imparcialidade e, por seguinte, a igualdade/universalidade dos direitos. Para tanto, vale-se de dois argumentos principais. Primeiro: o enlace do argumento do consenso com o da autonomia (pressuposto do discurso), procedendo-se, no primeiro, apenas a uma distribuição igual dos direitos que já se encontram fundamentados na última. Segundo: em um discurso ideal, além de pressuposto, a autonomia é um objeto elementar de interesse humano que encontraria a aprovação de todos.

Por fim, o argumento da democracia, que é composto por três premissas: a democracia é o melhor locus para a realização de uma racionalidade discursiva; a democracia, por outro lado, somente é possível mediante o exercício igual e pleno de direitos humanos e fundamen- 


\section{Humanos}

Democracia

tais políticos; e tais direitos somente podem ser dessa forma exercidos, ao fim e ao cabo, em que há a garantia de direitos humanos e fundamentais não políticos, dentre os quais os direitos à vida, ao mínimo existencial e a uma certa formação.

Conclui o autor, assim, haver uma união inseparável, apesar das tensões, entre direitos humanos e fundamentais e democracia, estado constitucional democrático. É certo, em vista disso, que a teoria do discurso permite não apenas a fundamentação daqueles direitos, mas do estado democrático, da democracia.

É possível observar que a matriz dessa fundamentação dos direitos humanos, ainda que com base discursiva, é kantiana e, desse modo, liberal. Tal fato é expressamente reconhecido pelo autor, que, entretanto, esclarece: toda fundamentação tem de se apoiar em algo, sendo tão boa, na verdade, quanto as premissas sobre as quais se apoia (ALEXY, 2015b).

O autor reconhece, igualmente, que a sua fundamentação jusfilosófica dos direitos humanos não deixa de ser metafísica, quer dizer, não é puramente naturalística, calcada em dados observáveis do mundo exterior, interior e social. Classifica-a, porém, como uma metafísica construtiva (não enfática, de salvação ou elevação), racional e universal (ALEXY, 2015c).

Esses dois aspectos - caráter metafísico e ideológico da fundamentação - são deveras importantes, mas não interessam aprofundar aqui. O objetivo, conforme anunciado inicialmente, é observar, na teoria estudada, a relação de complementaridade entre a fundamentação e a efetivação dos direitos humanos.

Fundamenta-se um direito com vistas à sua efetivação, e, ao efetivar-se um direito, pressupõe-se ou discute-se, conforme o caso, o seu fundamento. Assim, a fundamentação dos direitos humanos é um problema teórico com consequências práticas. Quanto mais duvidosa é uma fundamentação, ou menor o consenso em torno dela, mais importante ela é, afirma Alexy (2015a).

Não somente, todavia. Mesmo em situações nas quais não paire dúvida sobre a fundamentação dos direitos humanos, a teoria do discurso pode desempenhar papel útil na efetivação desses direitos. Em uma situação na qual colidam direitos, ela é uma ferramenta adequada para o sopesamento racional e, portanto, correto, à luz dos fundamentos dos direitos envolvidos e das condições do caso concreto, podendo-se cogitar, também, a situação em que a efetivação de um direito seja, habitual ou casuisticamente, negada, fornecendo a teoria discursiva, nesse caso elementos para afastar os argumentos irracionais e injustos, além de servir de base para sustentar a própria posição e dignidade do participante do discurso ali prejudicado.

A teoria do discurso é uma teoria da razão prática. Nela, fundamentar e efetivar direitos são questões práticas. Questões diferentes, mas práticas, ligadas à mesma razão, à razão prática. Na base dessas duas questões, que podem ser vistas como uma sucessão lógica ou mesmo (virtualmente) cronológica, reside o mesmo esquema racional de correção prática, moral e jurídica, em uma relação de continuidade e - mais - como visto, complementaridade. 


\section{CONSIDERAÇÕES FINAIS}

Para proceder a uma leitura da fundamentação dos direitos humanos, segundo Alexy, primeiramente situou-se o jusfilósofo germânico no movimento pós-positivista, ou não positivista, como ele mesmo prefere (ALEXY, 2014). A preocupação com o caráter prático da ciência do Direito fez com que o autor incursionasse no mundo dos valores, buscando superar o relativismo moral do método positivista por meio de procedimentos racionais. A ideia fundamental é que a razão prática é possível.

Daí a teoria do discurso (prático, racional), a base do pensamento do mestre alemão nas diversas vertentes da sua Teoria do Direito: a argumentação jurídica, a interpretação e a aplicação dos direitos fundamentais, conceito e validade do direito e, o objeto deste artigo, a fundamentação dos direitos humanos.

A princípio uma questão teórica - a fundamentação dos direitos humanos - apresenta consequências práticas. Fundamenta-se um direito que se pretende ver efetivado. Uma fundamentação sólida, em torno da qual se forme amplo consenso, conduz a uma efetivação segura, isto é, mais espontânea, menos conflituosa e questionável. De outro lado, na efetivação de um direito acha-se pressuposta a sua fundamentação, a qual, se duvidosa, abre espaço à consagração de soluções irracionais e injustas.

Nesse passo, ao submeter a fundamentação dos direitos humanos à teoria do discurso, Alexy, coerente com seus marcos teóricos e, notadamente, sua teoria sobre a argumentação jurídica, interpretação e aplicação dos direitos fundamentais, amalgama também a fundamentação dos direitos à racionalidade discursiva, prática.

Assim é que, no pensamento de Alexy, a razão prática, longe de ser apenas um adendo ou post scriptum ao positivismo jurídico - intentando delinear uma explicação racional para o processo de interpretação e aplicação do direito -. na verdade permeia a própria natureza do fenômeno jurídico, desde a construção dos seus fundamentos. Em Alexy, fundamentação e efetivação dos direitos humanos complementam-se não somente por, em tese, pressuporem-se reciprocamente, mas, sobretudo, por integrarem, coerentemente, o mesmo discurso prático-racional.

\section{REFERÊNCIAS}

ALEXY, Robert. Conceito e validade do direito. Organização Ernesto Garzón Valdés et al. Tradução Gercélia Batista de Oliveira Mendes. Revisão da tradução Karina Jannini. São Paulo: WMF Martins Fontes, 2009. Título original: Begriff und Geltung des Rechts.

ALEXY, Robert. Constitucionalismo discursivo. Organização e tradução Luís Afonso Heck. 4. ed. Porto Alegre: Livraria do Advogado, 2015a.

ALEXY, Robert. Direito, razão e discurso: estudos para a filosofia do direito. Tradução e revisão Luís Afonso Heck. 2. ed. Porto Alegre: Livraria do Advogado, 2015b. Título original: Recht, Vernunft, Diskurs: Studien zur Rechtsphilosophie.

ALEXY, Robert. O conceito e a natureza do direito. Tradução Thomas da Rosa de Bustamante. São Paulo: Marcial Pons, 2014. Tradução de El concepto y la naturaleza del derecho.

ALEXY, Robert. Teoria da argumentação jurídica: a teoria do discurso racional como teoria da fundamentação jurídica. Tradução Zilda Hutchinson Schild Silva. Revisão técnica da tradução e introdução à edição brasileira Cláudia Toledo. 3. ed. Rio de Janeiro: Forense, 2013. Tradução de Theorie der juristischen Argumentation.

ALEXY, Robert. Teoria Discursiva do Direito. Organização, tradução e estudo introdutório Alexandre Travessoni Gomes Trivisonno. 2. ed. Rio de Janeiro: Forense Universitária, 2015c. Tradução de Eine Theorie des praktischen Diskurses und andere. 
ALEXY, Robert. Teoria dos direitos fundamentais. Tradução Virgílio Afonso da Silva. 2. ed. São Paulo: Malheiros, 2011. Tradução da 5 a edição alemã de Theorie der Grundrechte.

BARROSO, Luís Roberto. Grandes transformações do direito contemporâneo e o pensamento de Robert Alexy. In: ALEXY, Robert. Princípios formais: e outros aspectos da Teoria Discursiva do Direito. Organização Alexandre Travessoni Gomes Trivisonno, Aziz Tuffi Saliba e Mônica Sette Lopes. Rio de Janeiro: Forense Universitária, 2014. p. 69-99.

BOBBIO, Norberto. A era dos direitos. Tradução Carlos Nelson Coutinho. Rio de Janeiro: Elsevier, 2004. Tradução de L'étà dei Diritti.

BOBBIO, Norberto. Da estrutura à função: novos estudos de Teoria do Direito. Tradução Daniela Baccaccia Versiani. Revisão técnica Orlando Seixas Bechara e Renata Nagamine. Barueri, SP: Manole, 2007. Título original: Dalla struttura alla funzione.

BOBBIO, Norberto. Direito e poder. Tradução Nilson Moulin. São Paulo: Editora Unesp, 2008. Título original: Diritto e potere.

BOBBIO, Norberto. O positivismo jurídico: lições de filosofia do direito. Compiladas por Nello Morra. Tradução e notas Márcio Pugliesi, Edson Bini, Carlos E. Rodrigues. São Paulo: Ícone, 1995.

CANÇADO TRINDADE. Antonio Augusto. A humanização do direito internacional. 2. ed. Belo Horizonte: Del Rey, 2015.

FARALLI, Carla. A filosofia contemporânea do direito: temas e desafios. Tradução Candice Premaor Gullo. Revisão da tradução Silvana Cobucci Leite. São Paulo: WMF Martins Fontes, 2006. Título original: La filosofia del diritto contemporanea.

GOYARD-FABRE, Simone. Filosofia crítica e razão jurídica. Tradução Maria Ermantina de Almeida Prado Galvão. Revisão da tradução Márcia Valéria Martinez de Aguiar. São Paulo: Martins Fontes, 2006. Título original: Philosophie critique et raison juridique.

LOSANO, Mario, G. Introdução. In: O problema da justiça. Tradução João Baptista Machado. 5. ed. São Paulo: Martins Fontes, 2011. p. VII-XXXIII. Título original: Das Problem der Gerechtigkeit.

LOSANO, Mario G. Nota preambular. In: KELSEN, Hans. A justiça e o direito natural. Tradução João Baptista Machado. Coimbra: Almedina, 2009, p. 7-39. Tradução do "Apêndice" da 2a edição alemã, de 1960, da Teoria Pura do Direito.

MARYIOLI, Aglaé. A reconstrução habermasiana do direito. In: BILLIER, Jean-Cassien; MARYIOLI, Aglaé. História da filosofia do direito. Tradução Maurício de Andrade. Barueri, SP: Manole, 2005. p. 429-439. Tradução de: Historie de la philosophie du droit.

MORRISON, Wayne. Filosofia do direito: dos gregos ao pós-modernismo. Tradução Jefferson Luiz Camargo. Revisão técnica Gildo Sá Leitão Rios. São Paulo: Martins Fontes, 2006. Título original: Jurisprudence: from the Greeks to post-modernism.

PALOMBELLA, Gianluigi. Filosofia do direito. Tradução Ivone C. Benedetti. Revisão técnica Ari Solon. São Paulo: Martins Fontes, 2005. Título original: Filosofia del diritto.

SANTOS, Boaventura de Sousa. Se Deus fosse um ativista dos direitos humanos. 2. ed. São Paulo: Cortez, 2014.

SEGATO, Rita Laura. Antropologia e direitos humanos: alteridade e ética no movimento de expansão dos direitos universais, Mana, 12 (1), p. 207-236, 2006.

TOLEDO, Cláudia. Apresentação à edição brasileira. In: ALEXY, Robert. Teoria da argumentação jurídica: a teoria do discurso racional como teoria da fundamentação jurídica. Tradução Zilda Hutchinson Schild Silva. Revisão técnica da tradução e introdução à edição brasileira Cláudia Toledo. 3. ed. Rio de Janeiro: Forense, 2013. p. 1-18. Tradução de: Theorie der juristischen Argumentation.

TORRADO, Jesús Lima. El fundamento de los derechos humanos. Argumenta: Revista do Programa de Mestrado em Ciência Jurídica, Jacarezinho: Universidade Estadual do Norte do Paraná - UENP, n. 16, p. 223-246, jan./jul. 2012.

TRIVISONNO, Alexandre Travessoni Gomes. Nota sobre a organização e a tradução. In: ALEXY, Robert. Teoria Discursiva do Direito. Organização, tradução e estudo introdutório Alexandre Travessoni Gomes Trivisonno. 2. ed. Rio de Janeiro: Forense Universitária, 2015a. p. XV-XXI. Tradução de: Eine Theorie des praktischen Diskurses und andere.

TRIVISONNO, Alexandre Travessoni Gomes. Estudo introdutório: A Teoria Discursiva do Direito de Alexy e as duas questões fundamentais da filosofia do direito. In: ALEXY, Robert. Teoria Discursiva do Direito. Organização, tradução e estudo introdutório Alexandre Travessoni Gomes Trivisonno. 2. ed. Rio de Janeiro: Forense Universitária, 2015b. p. 1-32. Tradução de: Eine Theorie des praktischen Diskurses und andere. 